УДК 378.178

\title{
БЕЗОПАСНОСТЬ ЦИФРОВЫХ ОБРАЗОВАТЕЛЬНЫХ СРЕДСТВ ДЛЯ СОЦИАЛЬНО-ПСИХОЛОГИЧЕСКОГО ЗДОРОВЬЯ СТУДЕНТОВ
}

Калегина Юлия Владимировна к.П.н., доцент

Ханжина Ольга Анатольевна к.П.н., доцент

ФГАОУ ВО «Южно-Уральский государственный университет (НИУ)»

\begin{abstract}
Аннотация: Поиск способов безопасного внедрения ЦОС в образовательный процесс университета стал основной целью исследования, проведенного на кафедре БЖД Южно-Уральского государственного университета. В статье рассмотрены результаты пилотажного эксперимента по изучению предпочтений студентов в выборе цифровых образовательных средств, проанализированы результаты опроса студентов о влиянии цифровых образовательных средств на социальный и психологический аспекты их здоровья, даны рекомендации по снижению негативного воздействия цифровых образовательных средств на здоровье студентов.
\end{abstract}

Ключевые слова: образовательный процесс университета, цифровые образовательные средства, социально-психологическое здоровье студентов.

\section{SECURITY OF DIGITAL EDUCATIONAL TOOLS FOR THE SOCIO-PSYCHOLOGICAL HEALTH OF STUDENTS}

\section{Kalegina Yulia Vladimirovna Khanzhina Olga Anatolievna}

\begin{abstract}
The search for ways to safely implement the DSP in the educational process of the university was the main goal of the study conducted at the Department of Safety Life of South Ural State University. The article considers the results of a pilot experiment to study students 'preferences in choosing digital educational tools, analyzes the results of a survey of students about the impact of digital educational tools on the social and psychological aspects of their health, and provides
\end{abstract}


recommendations for reducing the negative impact of digital educational tools on students' health.

Key words: university educational process, digital educational tools, sociopsychological health of students.

Цифровизация всех сфер жизнедеятельности человека - процесс неизбежный. Как социальное благо, цифровые средства постепенно интегрируются и в сферу высшего образования. Пандемия 2020 года способствовала приданию процессу интеграции революционного характера. Bсе имеющие информационный потенциал цифровые образовательные средства (далее ЦОС) были задействованы в качестве ресурсов обучения. В результате ЦОС вынужденно, но быстро стали для всех участников образовательных отношений в высшей школе альтернативой живому учебнопедагогическому взаимодействию. Достаточный период применения ЦОС в образовательном процессе университета проиллюстрировал и проблемы, связанные с их применением, прогнозируемые исследователями $[1,3,5]$ В первую очередь, это проблемы социально-психологического здоровья студентов, находящихся в самом сенситивном для восприятия информации, живого общения, формирования мировоззрения, приобщения к социальным ценностям, подтверждения теории в социально-профессиональной практике. Социально-психологические проблемы здоровья корректировались в аудиторном образовательном процессе через социальную поддержку, учебнопедагогическое взаимодействие. ЦОС не стали их заменой. Но пандемия 2020 года усилила значение в образовательном процессе не просто информационных технологий, а именно цифровых образовательных средств. ЦОС активно продемонстрировали в этот период свои преимущества:

- они гибкие и мобильные,

- у учащегося есть доступ к образовательному процессу в любой точке Земли, где есть интернет,

- их удобно использовать в организации индивидуального режима, темпа обучения [6].

Очевидно, что ЦОС останутся и после выхода социума из пандемии. Внедрение любой новации в образовательный процесс требует ее проверки на безопасность применения. Такого исследования ЦОС в полной мере перед пандемией осуществлено не было. Таким образом обострилось противоречие между неизбежностью внедрения ЦОС и отсутствия описания безопасных для 
социально-психологического здоровья студентов условий этого внедрения.

Поиск способов безопасного внедрения ЦОС в образовательный процесс университета стал основной целью исследования, проведенного на кафедре БЖД Южно-Уральского государственного университета. На первом этапе достижения цели авторы статьи сосредоточились на выявлении вредных для социально-психологического здоровья студентов свойств ЦОС. В ходе работы использованы методы естественного и лабораторного наблюдения, опрос, экспертиза, анализ накопленного теоретического и практического опыта по проблеме исследования $[2,4]$. Для решения поставленной задачи были

- изучены предпочтения студентов в применении различных видов ЦОС в образовательном процессе (в том числе в процессе самообразования);

- установлены потенциально вредные для здоровья студентов свойства ЦОС;

- выявлены связи применения ЦОС с изменениями в социальнопсихологическом здоровье студентов.

Анализ практики применения ЦОС показал, что в образовательный процесс в высшем образовании обеспечен самыми разнообразными ЦОС:

- открытые образовательные программы и курсы,

- электронные учебные пособия,

- средства компьютерного моделирования,

- Интернет-сайты,

- открытые площадки (yaklass.ru, фоксфорд, uchi.ru и др.)

В научных публикациях эти ЦОС были исследователями классифицированы следующим образом.

1. Информационные ЦОС - носители упорядоченной информации.

2. Тренирующие ЦОС - система тренажеров для отработки навыков.

3. Вычислительно-измерительные ЦОС - калькуляторы разных форматов.

4. Контролирующие ЦОС - выявляют качество знаний.

5. Коммуникационные ЦОС - связь участников образовательного процесса посредством сети.

6. Мотивационные ЦОС - различные дневники, списки дел и таймеры: в общем, все для организации рабочего времени и поддержания себя на «плаву».

Все они имеют разный рейтинг популярности среди студентов и преподавателей.

Вместе с тем, все участники образовательного процесса указывают на их влияние на социально-психологическое состояние их здоровья. Базой 
исследования стали студенты ЮУрГУ. Значимые факторы влияния ЦОС на социально-психологическое здоровье студентов были уточнены в ходе беседы со студентами и преподавателями и, после обработки, были обобшены в перечень требований необходимых к учету педагогом, применяющим в образовательном процессе ЦОС:

- требуемая сосредоточенность (продолжительность удержания внимания);

- необходимый объем внимания (количество объектов, удерживаемых одновременно в поле зрения);

- необходимая скорость переключения внимания (достаточная оперативность);

- необходимость абстрагироваться от отвлекающих факторов (ссылки, рекламные ролики, интернет-мусор);

- возможность влиять на познавательную активность студента (увлекательность, способность вызывать интерес, провокация самостоятельного поиска ответа на вопросы);

- эмоциональная насыщенность образовательного средства (наглядность и иллюстративность, воздействие на чувства);

- баланс обучающей и развлекательной функций (соответствие задачи обучения и воспитания применяемым средствам обучения и развлечения);

- социальная приемлемость информации и способов деятельности (адекватность содержания образования социальным и профессиональным ценностям);

- правомерность информации и способов деятельности (адекватность содержания образования правовым нормам, нормам научной этики),

- возможность межличностных контактов (провокация уточнения мнения сообщества по вопросам, требование наблюдения за поведением других),

- возможность объективного структурирования (вариативность в содержании образования и способах его представления, иллюстрирования),

- характер информации в ЦОС (ее научность, педагогическая целесообразность, возрастная доступность, системность изложения).

Формат исследования для выявления связей применения ЦОС с изменениями в социально-психологическом здоровье студентов - google-опрос. Отвечать на вопросы опросника респондент должен был анонимно, самостоятельно, время на ответ не ограничено. 
Структура диагностического средства: опросник состоял из блоков вопросов, связанных с общими сведениями, с показателями социального и психологического аспектов здоровья. Было предложено 23 вопроса (21 вопрос подразумевал выбор ответа из предложенных вариантов, два вопроса были общими и предполагали развёрнутый ответ демонстрирующий предпочтение респондента в применении ЦОС).

Результаты опроса позволяют сделать следующие выводы.

1. Респонденты отдают предпочтение платформе Zoom, она обогнала по популярности в использовании Google Meeting, Skype и Discord.

2. Студенты не хотят обучаться дистанционно на постоянной основе, отдают предпочтение смешанному формату образования.

3. Студенты замечают существенное различие в качестве образовательного процесса в цифровом и аудиторном формате: аудиторный формат, по их мнению, эффективнее.

4. На открытые вопросы «Какие бы изменения вы внесли для улучшения дистанционного образования?» и «Какие сложности социальнопсихологического характера у Вас возникли во время дистанционного обучения с применением ЦОС?» наиболее популярными ответами стали следующие высказывания:

«Перевести в дистанционный формат с применением ЦОС часть предметов, не требующих живой педагогической демонстрации».

«Следует обучить преподавателей в пользовании ЦОС, предложить им методики преподавания предметов, разработанные специально для цифрового формата, а не предлагать подстраивать аудиторные к цифровому формату. Тогда учебные занятия были бы интереснее и качественнее».

«Пересмотреть требования по объему и продолжительности самостоятельной работы студентов с использованием ЦОС: по сравнению с офлайн режимом на дистанционном образовании нам задавали гораздо больше, нагрузка была чрезмерной».

«Улучшение функционирования платформ коммуникации (иногда бывают технические проблемы с посещением занятия, с отправкой задания и др.)».

«Не успевали за речью лектора, не было возможности задать вопрос по содержанию лекции и получить на него ответ в момент возникновения вопроса, материал хуже усваивался». 
«Снизилась мотивация поиска дополнительной информации по теме учебного занятия, возникло ощущение, что весь учебный материал представлен в ЦОС».

«Исказилось представление о своем образовательном рейтинге в группе, стало невозможно дать собственную оценку своих и чужих успехов, идей неудач, ошибок по учебному предмету, это усиливало тревожность».

«Исказилось ощущение времени при выполнении заданий, просмотре лекций с применением ЦОС, возникло ощущение опаздывания или торопливости при выполнении задания».

«Рассеялось внимание, постоянно отвлекался на форму представления материала, цветовое решение, сопровождающие рисунки, музыку, сообщения в социальных сетях, ухудшилось восприятие материала без личного живого общения с преподавателем и одногруппниками».

«Большое количество раздражающих технических неполадок, ЦОС требуют тщательных доработок».

Для комплексной разработки рекомендаций требуется проведение более глубокого исследования и более тщательный анализ результатов уже проведенного пилотажного исследования. В настоящий момент анализ результатов опроса, личная беседа с респондентами также позволили сформулировать ряд рекомендаций для студентов.

1. Выделите рабочее время за компьютером и отделите его от остальной жизни.

2. Создать себе максимально комфортную рабочую обстановку: свет, удобное кресло или стул, стол органичной для Вас высоты и площади.

3. Оставьте на столе лишь необходимые для учебы вещи: ручки, тетради, ноутбук и так далее.

4. Решите, нужна ли Вам музыка для выполнения задания или тишина.

5. Не позволяйте себе постоянно проверять социальные сети и посещать сайты, не связанные с учебой.

6. Фиксируйте все вопросы и замечания, возникающие в ходе учебного занятия с применением ЦОС в тетради, чтобы в ближайшее время найти ответы на них у преподавателя или самостоятельно.

7. Постарайтесь фиксировать свои успехи, чтобы пересматривать их и мотивировать себя двигаться дальше. 
8. Распишите себе время для встреч с друзьями, одногруппниками чтобы поддерживать, развивать социальные контакты и время для консультаций с преподавателем.

9. Запланируйте часы отдыха от всех цифровых средств, не только образовательных: откладывайте телефон, выключайте телевизор, компьютер совсем в течение дня несколько раз.

\section{Список литературы}

1. Вербицкий А.А. Цифровое обучение: проблемы, риски и перспективы / А.А. Вербицкий // Электронный научно-публицистический журнал «Ното Cyberus». 2019. №1(6). [Электронный pecypc]: http://journal.homocyberus. ru/Verbitskiy_AA_1_2019.

2. Сидоров А.И., Калегина Ю.В. Направления модернизации образования в сфере безопасности // Вестник МАНЭБ. 2018. Т. 23. № 2. С. 193-197.

3. Сидоров А.И. Проблема безопасности цифровых образовательных средств и векторы ее решения / А.И. Сидоров, Тягунова // В сборнике: Техносферная безопасность как комплексная научная и образовательная проблема. 2018. С. 76-80.

4. Тягунова Ю.В. Здоровье студента как показатель качества проектирования образовательного процесса университета //Вестник ЮжноУральского государственного университета. Серия: Образование. Педагогические науки. 2016. Т. 8. № 3. С. 51-56.

5. Устюжанина Е.В. Цифровизация образовательной среды: возможности и угрозы / Е.В. Устюжанина, С.Г. Евсюков // Вестник Российского экономического университета им. Г.В. Плеханова, 2018. № : 1 (97). с.3-12.

6. Pedagogical evaluation of digital tools' safety in education / Kalegina, Y.V // INTED Proceedings. 2019. P.373-381.

() Ю.В. Калегина, О.А. Ханжина, 2021 